\title{
Technology in rural continuing medical education
}

\author{
Using the information highway to close the distance
}

James Yan (Meds 2015)

Faculty Reviewer: Dr Ken W Milne, MD, MSc, CCFP(EM), FCFP (Division of Emergency Medicine)

The career of medicine is often described as a career involving lifelong learning. Knowledge and skills are constantly updated and "best practices" are continually redefined based off the latest advances in medical research and guidelines. ${ }^{1}$ Typically physicians are engaged in this continuing medical education (CME) via both formal and informal methods, and this is a career-long process. ${ }^{1}$ However, it has been documented that access to CME opportunities is much more limited for rural practising physicians than their urban colleagues. ${ }^{2,3}$ Rural physicians often practise and live in geographically isolated areas with fewer resources and greater distances between networks of colleagues. ${ }^{2-4}$ The geographic distance from urban centres and the generally smaller populations of rural communities are disincentives for formal CME programs to be held in rural centres. ${ }^{5}$ Rural physicians also experience additional difficulties in the form of higher costs of transport as well as increased opportunity costs of being away from practise, long travel times leading to less time with family, and greater difficulty in finding substitutes to cover their clinical responsibilities. ${ }^{3}$ These obstacles can be a source of stress and professional isolation for rural physicians who must keep up their skills and strive to provide optimal care for their patients. Rural physicians, relative to their urban colleagues, report less participation in formal CME events. ${ }^{5}$

Similarly, rural physicians are also at a disadvantage when conducting medical research. Resource distribution for medical research is uneven and rural sites often receive far less funding than urban centres. ${ }^{6}$ It is also an obstacle for any sort of coordinating body or organization to provide cohesion and coordination to rural medical research efforts. Collaboration and communication can be stalled by the large distances between local health networks. The difficulties of establishing rurally focused medical research add to the challenge in delivering proper medical care to these communities. In Canada, rural populations have been shown to have lower life expectancy and overall poorer health. ${ }^{6,7}$ There are also often different prevalence and incidence of certain diseases in rural regions as compared to urban populations due to differences in industry, environment, nutritional access, and other social determinants of health. ${ }^{3,6}$ Due to lack of access to a conveniently reachable specialist support network for referral, medical practitioners in their local populations have to have more knowledge and expertise in a broader clinical scope in order to manage the health of rural populations. ${ }^{8,9}$ Improving research that recognizes the differences between urban and rural health care needs is needed in order to develop a best practises methods for the provision of health care to rural Canadians.
The recent rapid surge of information technology development has been a great boon to improving access for rural and remote physicians. ${ }^{10-13}$ The growing focus on mobile and wireless capability seems to address the needs of physicians on the go or in distant locations. ${ }^{13}$ These devices have created new roads for people to connect, and rural physicians should be power users in this regard. ${ }^{13}$ As the capabilities to transfer and share information continue to evolve, there is incredible potential to use the information highway to shrink the geographic distance that separates rural and remote physicians from resources and colleagues.

There are a number of ways in which technology is already showing its influence. Better data compression, improved broadband speeds, and high-definition monitors have allowed remotely distributed sites to video conference, consult images, or even provide simulation teaching. Distance learning can create continual education opportunities for remote physicians who cannot spare the time to leave their community without care. ${ }^{12}$ The open availability of online learning can also allow rural physicians to gain access to a wider variety of skills to learn. Physicians are also rapidly utilizing social media to engage each other globally. ${ }^{13}$ Doctors who find that they cannot attend a specific conference of interest can still join the conversation by searching up that conference's hashtag (\#) online. ${ }^{14,15}$ Websites like www.symplur.com work to inform health care professionals of various conferences' and moderated online discussions' Twitter hashtags. ${ }^{15}$ Finally, as online communities become more prominent, it is only natural that groups of physicians adopt this technology as well. While the interactions may be virtual, online communities still allow physicians to collaborate and network. The Gateway Rural Health Research Initiative is a Canadian example that connects rural communities and health centres together in order to drive rural health research capabilities. ${ }^{16}$

The world of rural medicine is still undergoing a process to improve the training opportunities available to its physicians. While it is a difficult undertaking to overcome the wide geographic distribution that challenges Canadian rural doctors, the use of new communications technology is helping to bridge that gap. Progressions in information technology can address the barriers faced by rural physicians pursuing CME by reducing the need to travel, lowering costs, and connecting distant networks. It is challenging to encourage physician participation in and endorsement of the novel approaches to obtain training via information technology. As we move into the future, it is reasonable to surmise that improved access to continual training for rural physicians will help deliver better quality health care to the rural and remote populations of Canada. 


\section{FEATURE ARTICLE}

\section{REFERENCES}

1. Bankey R, Campbell C. Lifelong learning white paper - supporting physician lifelong learning: strategies, tools and recommendations [Internet]. Ottawa: Royal College of Physicians and Surgeons of Canada; 2008 [cited 2013 Nov 1]. 6 p. Available from: http://rcpsc.medical.org/clip/clip_research/publications/index. php

2. Sargeant JM. Medical education for rural areas: opportunities and challenges for information and communications technologies. J Postgrad Med. 2005;51(4):301-7.

3. Curran VR, Fleet L, Kirby F. Factors influencing rural health care professionals' access to continuing professional education. Aus J Rural Health. 2006 Mar; 14(2):51-5.

4. Lewkonia R. Educational implications of practice isolation. Med Educ. 2001 Dec;35(6):525-9.

5. Curran V, Hatcher L, Kirby F. CME needs of rural physicians. How do we compare with our urban counterparts? Can J Rural Med. 2000 S;5(3):131-8.

6. Pong RW. Rural Health Research in Canada: at the crossroads. Aus J Rural Health. 2001 Dec;8(5):261-5.

7. Rourke JT. Strategies to increase the enrolment of students of rural origin in medical school: recommendations from the Society of Rural Physicians of Canada. CMAJ. 2005 Dec;172(4):62-5.

8. Strasser R. Rural general practice: is it a distinct discipline? Aus
Fam Physician. 1995 May;24(5):870-6.

9. Rourke JT. Postgraduate training for rural family practice. Goals and opportunities. Can Fam Physician. 1996 June;42:1133-8.

10. Curran VR, Fleet L. A review of evaluation outcomes of web based continuing medical education. Med Ed. 2005 May;39(6):561-7.

11. Harden RM. Trends and the future of postgraduate medical education. Emerg Med J. 2006 Jan;23(10):798-802.

12. Ryan G, Lyon P, Kumar K, Bell J, Barnet S, Shaw T. Online CME: an effective alternative to face-to-face delivery. Med Teach. 2007;29(8):e251-7.

13. Greene J. Social Media and Physician Learning: is it all Twitter? Ann Emerg Med. 2013 Nov; 62(5):11A-13A.

14. McKendrick DR, Cumming GP, Lee AJ. Increased use of Twitter at a medical conference: a report and a review of the educational opportunities. J Med Internet Res. 2012 Dec;14(6):e176.

15. Neill A, Cronin JJ, Brannigan D, O’Sullivan R, Cadogan M. The impact of social media on a major international emergency medicine conference. Emerg Med J. 2013 Feb;0:1-4.

16. Gateway Rural Health Research Institute [Internet]. Seaforth (ON): Gateway Rural Health Research Institute; c2008. Gateway's frontline research advantage; 2018 Sep 26 [cited 2013 Nov 1]. Available from: http://www.gatewayresearch.ca/research. 